\title{
Neet aan 't werk, neet op sjoël, neet op training: NEET in Limburg in 2020
}

Citation for published version (APA):

Levels, M., Dicks, A., \& de Grip, A. (2020). Neet aan 't werk, neet op sjoël, neet op training: NEET in Limburg in 2020: Beschrijving, bepaling en beleidsadvies. ROA. ROA Fact Sheets No. 004 https://doi.org/10.26481/umarof.2020004

Document status and date:

Published: 30/06/2020

DOI:

10.26481/umarof.2020004

Document Version:

Publisher's PDF, also known as Version of record

\section{Please check the document version of this publication:}

- A submitted manuscript is the version of the article upon submission and before peer-review. There can be important differences between the submitted version and the official published version of record. People interested in the research are advised to contact the author for the final version of the publication, or visit the DOI to the publisher's website.

- The final author version and the galley proof are versions of the publication after peer review.

- The final published version features the final layout of the paper including the volume, issue and page numbers.

Link to publication

\footnotetext{
General rights rights.

- You may freely distribute the URL identifying the publication in the public portal. please follow below link for the End User Agreement:

www.umlib.nl/taverne-license

Take down policy

If you believe that this document breaches copyright please contact us at:

repository@maastrichtuniversity.nl

providing details and we will investigate your claim.
}

Copyright and moral rights for the publications made accessible in the public portal are retained by the authors and/or other copyright owners and it is a condition of accessing publications that users recognise and abide by the legal requirements associated with these

- Users may download and print one copy of any publication from the public portal for the purpose of private study or research.

- You may not further distribute the material or use it for any profit-making activity or commercial gain

If the publication is distributed under the terms of Article $25 \mathrm{fa}$ of the Dutch Copyright Act, indicated by the "Taverne" license above, 
Maastricht University ROA

Neet aan 't werk, neet op sjoël, neet op training:

NEET in Limburg in 2020

Beschrijving, bepaling en beleidsadvies

Mark Levels

Alexander Dicks

Andries de Grip

\section{ROA Factsheet}

ROA-F-2020/4

Researchcentrum voor Onderwijs en Arbeidsmarkt | ROA Research Centre For Education and the Labour Market / ROA 


\section{Neet aan 't werk, neet op sjoël, neet op training}

\section{Cijfers}

In 2018 lieten we in het kader van het

4Limburgprogramma zien dat Limburg verhoudingsgewijs een groot aantal jongeren kent zonder baan, opleiding of training (zogenaamde NEETs) én dat dit aantal tegen de landelijke trend in nog steeds groeit.' In 2015 kende Limburg zo'n 20.000 NEETs tussen de 15 en 27 jaar oud; ongeveer de helft van die groep jongeren is kwetsbaar en niet in staat de transitie van school naar werk te maken. Op verzoek van de provincie presenteren we in deze factssheet een update van deze cijfers. Bovendien doen we nieuwe analyses die ons enige interessante nieuwe inzichten verschaffen. We geven op basis van deze inzichten specifieke aanbevelingen voor beleid.

In Figuur 1 presenteren we eerst een update van de vergelijking van trends in verschillende Nederlandse provincies. De figuur laat - op basis van gegevens van het CBS - zien dat de percentages NEETs in de meeste provincies verder zijn gedaald. Deze landelijke trend is ingezet rond 2012, en markeert het einde van de gevolgen van de economische crises die in 2008 begonnen. De afwijkende trend voor Limburg (en in mindere mate Groningen) die we in de vorige analyse opmerkten, is tussen 2015 en 2018 verder versterkt. Hoewel ook in Limburg tussen 2016 en 2017 een lichte daling optrad, lijkt het percentage NEETs in Limburg te stabiliseren op een relatief hoog niveau.

In absolute aantallen is het beeld niet erg verbeterd. In october 2018 woonden er 154.421 jonge mensen tussen de 15 en 27 jaar in Limburg. Van hen konden we 20.219 jongeren identificeren als NEET. Het gaat dus om ongeveer 13\% van de totale bevolking. Zo'n 40\% (8.083) van deze NEETs woont in Maastricht. Wanneer we het percentage NEETs per gemeente bekijken, lijken er zes stedelijke hotspots te zijn:

1. Vaals (46\%)

2. Maastricht (29\%)

3. Kerkrade (14\%)

4. Heerlen (13\%)

5. Brunssum (11\%)

6. Sittard Geleen (11\%)

7. Venlo (11\%)

1 Levels, Mark, Andries de Grip \& Alexander Dicks (2018). NEETs in Limburg: trends, spreiding, en duiding. Research Centre for Education and the Labour Market. ROA Fact Sheets, ROA-F-2018/2.
In Figuur 2 presenteren we de ontwikkeling van het aantal NEETs in Limburgse gemeenten tussen 2015 en 2018. Uit deze figuur blijkt dat de gemeenten Vaals en Maastricht als enige van alle Limburgse gemeenten meer NEETs hebben gekregen. Verschillende gemeenten in Midden-Limburg (Echt-Susteren, Roerdalen, Roermond), en Zuid-Limburg (Gulpen-Wittem, Schinnen en Stein) hebben in 2018 minder NEETs dan in 2015.

Deze cijfers zijn informatief, maar geven evenwel een vertekend beeld. Niet alle NEETs zijn kwetsbaar. ${ }^{2} \mathrm{Om}$ beter te begrijpen welke NEETs kwetsbaar zijn, kunnen we de jongeren volgen gedurende de hele overgangsfase van school naar werk. Op basis van gegevens van het CBS over maandelijke activiteiten op school en op de arbeidsmarkt (tussen januari 2014 en eind 2018) kunnen we de totale NEET-populatie indelen in vier typen. We onderscheiden langdurige NEETs, nieuwkomers, onderwijsverlaters en werkverlaters. Langdurige NEETs zijn jongeren die het grootste deel van de afgelopen vijf jaar NEET zijn geweest. 27,6\% van de jongeren die in oktober 2018 NEET waren, valt in deze categorie. Dit is iets minder dan in 2015 (29,7\%). Nieuwkomers (ongeveer 40\%) zijn mensen die we het grootste deel van de vijf jaar niet kunnen observeren, wat betekent dat ze in die tijd naar Nederland zijn gekomen. In 2018 vertegenwoordigen nieuwkomers het grootste deel van de NEETs. De categorieën schoolverlaters en werkverlaters spreken voor zich, jongeren in deze categorieën waren af en toe NEET, maar volgden het grootste deel van de vijf jaar een opleiding (29\%) of hadden een baan $(3,5 \%)$. Het is belangrijk op te merken dat deze vier typen NEETs volgen uit de analyse van de gegevens en niet vooraf door ons zijn gedefiniëerd. Om tot de indeling in groepen te komen gebruiken we een analysetechniek die lijkt op datamining. Die procedure stelt ons in staat om patronen in gegevens te ontdekken zonder daarbij onze eigen verwachtingen aan de gegevens op te leggen. Onderzoekers selecteren dan welke typen het meest relevant zijn voor het onderzoek. Deze analyse leidde tot vier clusters.

In Figuur 3 presenteren we de typische patronen van school-naar-werk die horen bij de verschillende clusters. We zien hier bijvoorbeeld dat alle categorieën een korte

2 Dicks, Alexander \& Mark Levels (2018). NEET is een slechte indicator van kwetsbaarheid. Economisch Statistische Berichten, 103(4758), 95-95. 


\section{Factsheet}

Figuur 1

NEETs in verschillende Nederlandse provincies tussen 2005 en 2018

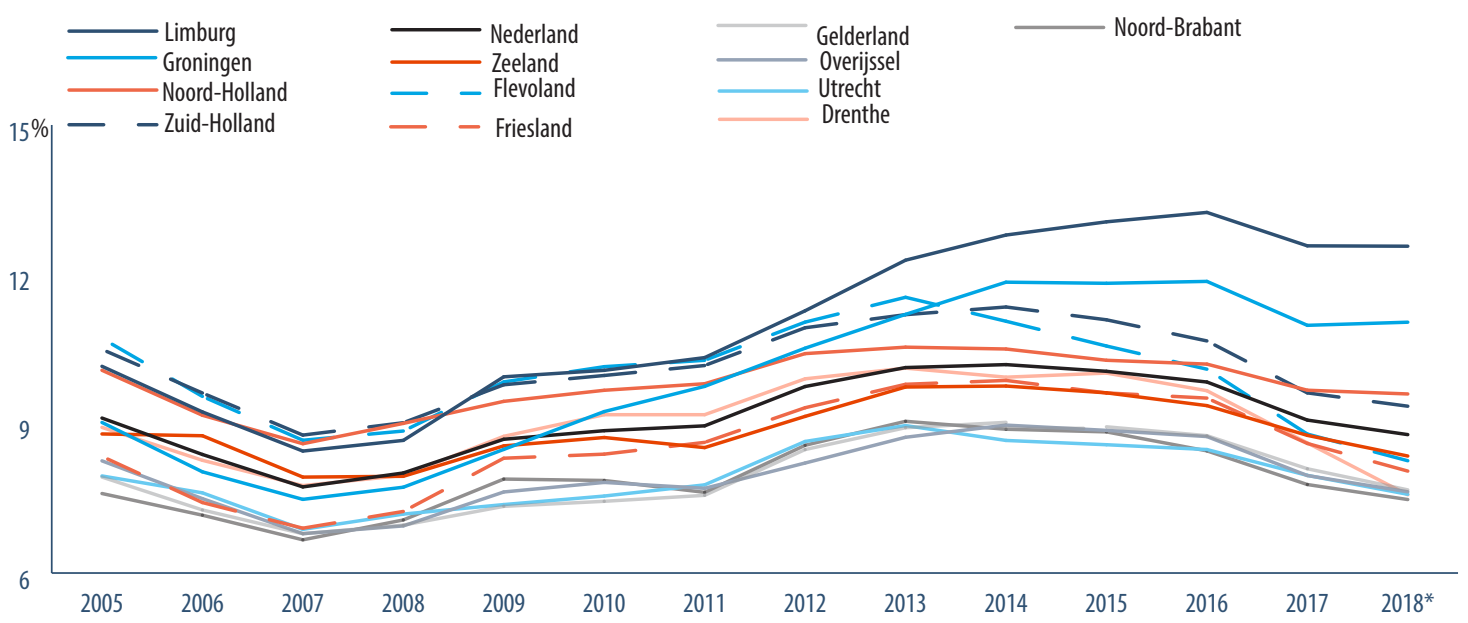

Figuur 2

NEET naar Limburgse gemeenten, in Oktober 2015, 2018 en ontwikkeling (\%)

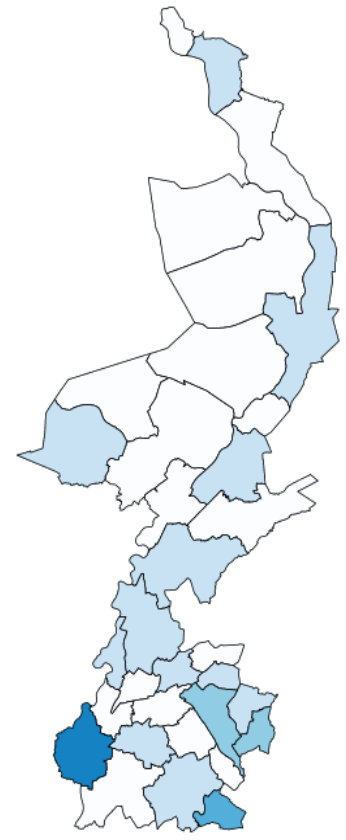

October 2015

$=30-100$

$\square 25-30$

$\square 20-25$

$\square 15-20$

$\square 10-15$

$\square 0-10$

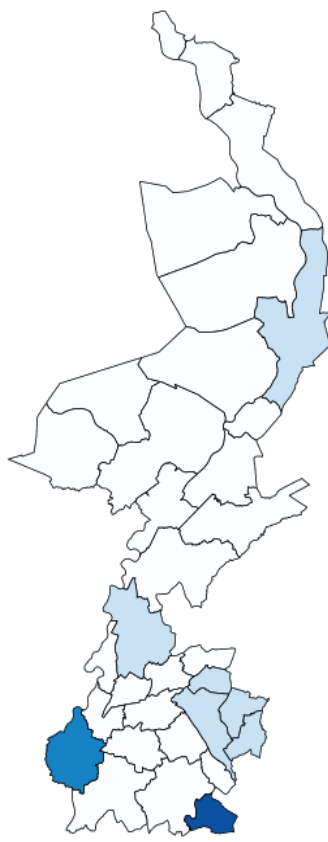

October 2018

$=30-100$

$\square 25-30$

$\square 20-25$

$\square 15-20$

$\square 10-15$

$\square 0-10$

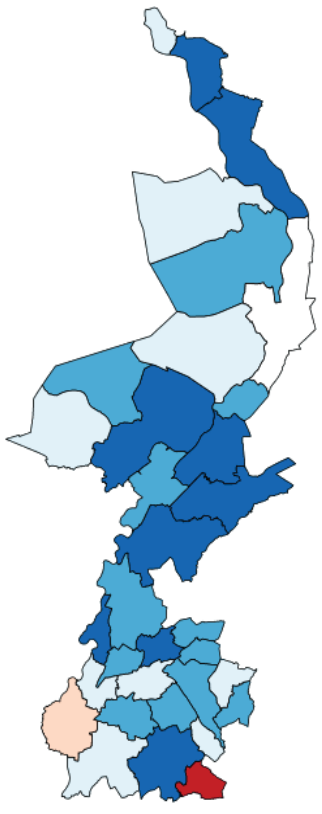

Groei 2015 - 2018

-25 - 100

$\square 15-25$

$\square 5-15$

$\square-5-5$

$\square-15--5$

$\square-25--15$

$\square-100--25$ 


\section{Neet aan 't werk, neet op sjoël, neet op training}

Figuur 3

Typische patronen voor de vier NEET groepen

Langdurig

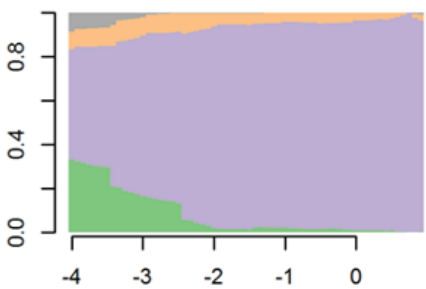

Onderwijsverlaters

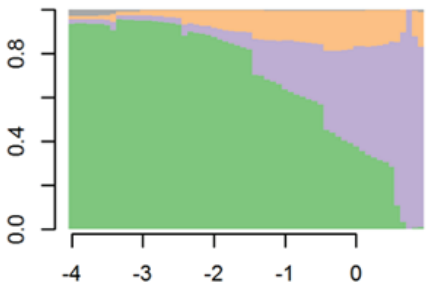

Nieuwkomers

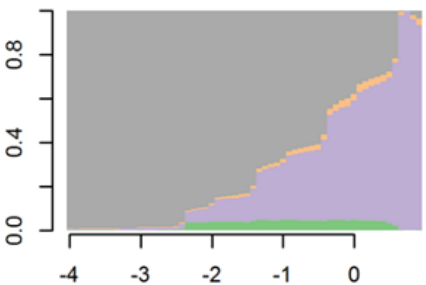

Werk

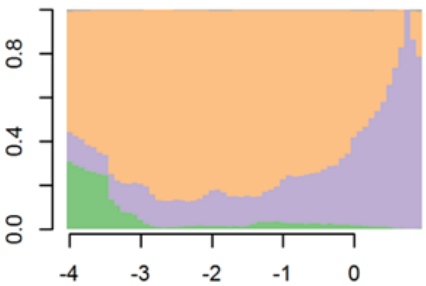

$\begin{array}{ll}\square \text { Onderwijs } & \square \text { Werk } \\ \square \text { NEET } & \square \text { Onbekend }\end{array}$

Figuur 4

Verdeling van NEET types in Limburgse gemeenten

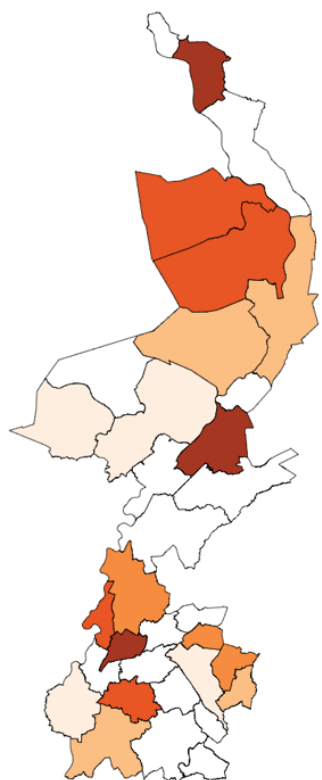

Werk
$-7.2-7.8$

$-7.2-7.8$
$-6.0-72$

$=5.2-6.0$

$\square 4.6-5.2$

No 4.6

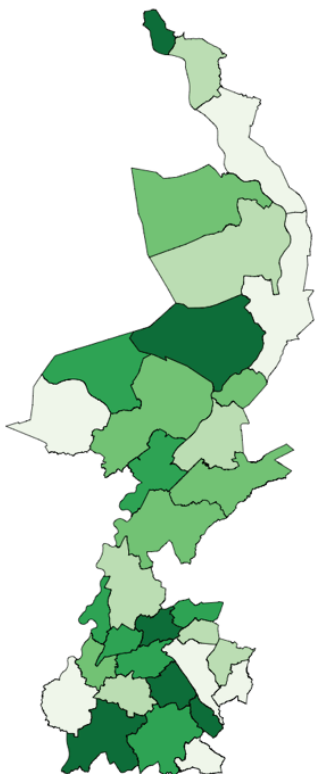

Onderwijs

$=50.7-58.8$

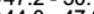

$\square 40.3-44.0$

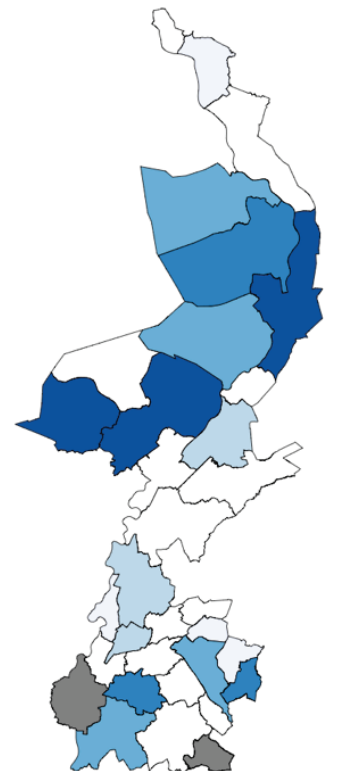

Nieuwkomers

$=18.1-26.9$

- $11.1-18.1$

$\square 10.6-11.6$

$8.1-10.6$

No data

Maastricht $(71 \%)$ en Vaals $(77 \%)$

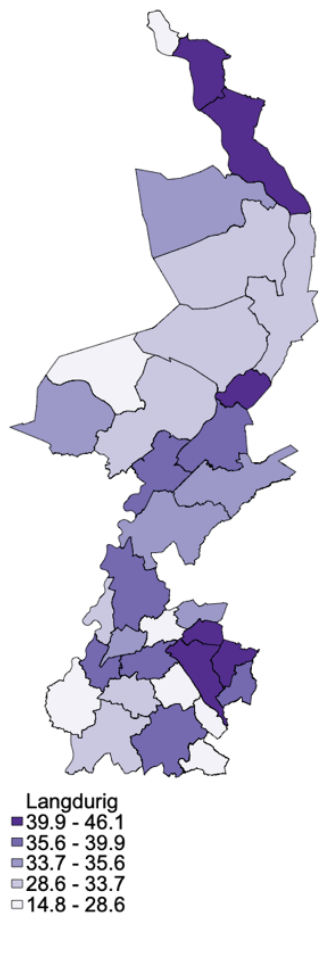




\section{Factsheet}

ROA-F-2020/4

of langere tijd NEET zijn (paars). Onderwijsverlatende NEETs zijn het grootste deel van het tijd onderwijsvolgend (groen), maar vinden geen aansluiting op de arbeidsmarkt (oranje). Werkverlatende NEETs besteedden het grootste deel van de tijd tussen begin 2014 en eind 2018 op de arbeidsmarkt, maar verloor op enig moment haar of zijn baan en werd NEET.

Als we de verdeling van de typen over de verschillende Limburgse gemeenten bezien (Figuur 4), valt op dat het grootste deel van de NEETs in Maastricht (71\%) nieuwkomer is. Hetzelfde geldt voor Vaals (77\%). In Maastricht is $15,8 \%$ van de NEETs langdurig NEET. Daarentegen vinden we langdurige NEETs vooral in de oude mijnstreken. In Heerlen bijvoorbeeld is $42 \%$ van de NEETs landurig NEET, en slechts 15\% nieuwkomer. Ook in de gemeenten Beesel, Bergen en Gennep en vinden we een relatief hoog aantal langdurige NEETs. In Roermond, Beek en Gennep vinden we in vergelijking veel NEETs die na een baan NEET worden. In Eijsden-Margraten, Simpelveld, Voerendaal, Schinnen, Peel en Maas, en Mook-Middelaar worden de meeste jonge NEETs dat via het onderwijs. We kunnen ook de verdeling van de clusters vergelijken tussen Limburgse RMC-regio's en zien of en in hoeverre we verschillende trends kunnen waarnemen (Tabel 1). We zien dan bijvoorbeeld dat het aantal NEETs dat als nieuwkomer te boek staat in Zuid-Limburg twee keer zo hoog is dan in Noord- en Midden-Limburg. In beide regio's is het aantal NEETs dat via het onderwijs of werk NEET wordt, afgenomen. We zien ook dat in 2018 er relatief meer langdurige NEETs in regio Noord- en Midden-Limburg woonden, hoewel hun aantal in absolute zin lager ligt. Waar in Zuid-Limburg het aantal langdurige NEETs iets is afgenomen, is dat aantal in Noorden Midden-Limburg iets toegenomen.
Tabel 1

Verdeling van NEET-types in Limburgse RMC-regio's (absoluten en percentages)

\begin{tabular}{|c|c|c|c|c|c|}
\hline \multirow{3}{*}{ NEET type } & \multirow{3}{*}{ Jaar } & \multicolumn{4}{|c|}{ RMC } \\
\hline & & \multicolumn{2}{|c|}{ Zuid-Limburg } & \multicolumn{2}{|c|}{$\begin{array}{l}\text { Noord- en Midden- } \\
\text { Limburg }\end{array}$} \\
\hline & & $\%$ & $\mathrm{~N}$ & $\%$ & $\mathrm{~N}$ \\
\hline \multirow[t]{2}{*}{ Langdurig } & 2015 & 28,12 & 4.326 & 33,66 & 2.085 \\
\hline & 2018 & 25,01 & 3.739 & 34,93 & 1.840 \\
\hline \multirow[t]{2}{*}{ Nieuwkomers } & 2015 & 34,74 & 5.344 & 12,25 & 759 \\
\hline & 2018 & 47,33 & 7.077 & 17,96 & 946 \\
\hline \multirow[t]{2}{*}{ Onderwijsverlaters } & 2015 & 32,47 & 4.995 & 44,5 & 2.757 \\
\hline & 2018 & 24,93 & 3.727 & 41,44 & 2.183 \\
\hline \multirow[t]{2}{*}{ Werkverlaters } & 2015 & 4,68 & 720 & 9,59 & 594 \\
\hline & 2018 & 2,73 & 408 & 5,68 & 299 \\
\hline
\end{tabular}

Deze conclusie wordt versterkt én genuanceerd door Figuur 5. Uit deze figuur blijkt dat de het aantal langdurige NEETs vooral in Noord-Limburgse gemeenten is toegenomen, en dan vooral in de gemeenten tussen Maas en Duitse grens. Maar ook in sommige ZuidLimburgse gemeenten nam het aantal langdurige NEETs toe: in Gulpen-Wittem, Nuth, Landgraaf, Meerssen en Stein. In Midden-Limburg is het aantal langdurige NEETs vooral in Roerdalen toegenomen.

\section{lets nadere duiding}

Laten we eens iets beter kijken naar de eigenschappen van de verschillende groepen NEETs. We kijken daartoe naar de gegevens die het CBS in registers verzameld. Zo kunnen we iets te weten komen over herkomst, opleidingsniveau en geslacht van jongeren. In Tabel 2 zien we de verdeling van de vier typen NEETs over de CBS herkomstgroepering. Het grootste deel van de NEETs is autochtoon (40\%); nog eens $38 \%$ is Westers migrant. Ongeveer 22\% van de Limburgse NEETs heeft een nietWesterse migratieachtergrond; het leeuwendeel van hen (2.231) komt uit niet nader gespecificeerde herkomstlanden.

In Tabel za laten we de belangrijkste herkomstlanden van Limburgse NEETs zien. Van alle langdurige NEETs is $60 \%$ van Nederlandse origine: beide ouders zijn in Nederland geboren. Van langdurige NEETs komen 6,11\% uit Duitsland; 3,76\% heeft een Marokkaanse achtergrond. 


\section{Neet aan 't werk, neet op sjoël, neet op training}

Figuur 5

Percentage langdurige NEET als deel van de totale populatie NEETs in oktober 2015 en 2018

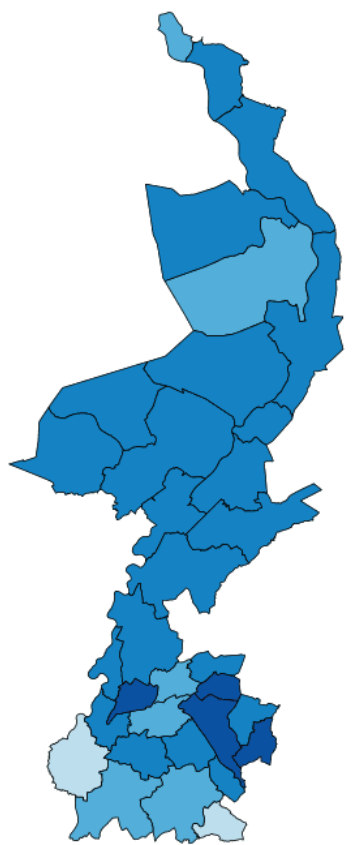

2015

$\square 40-50$

$\square 30-40$

$\square 20-30$

$\square 10-20$

$\square 0-10$

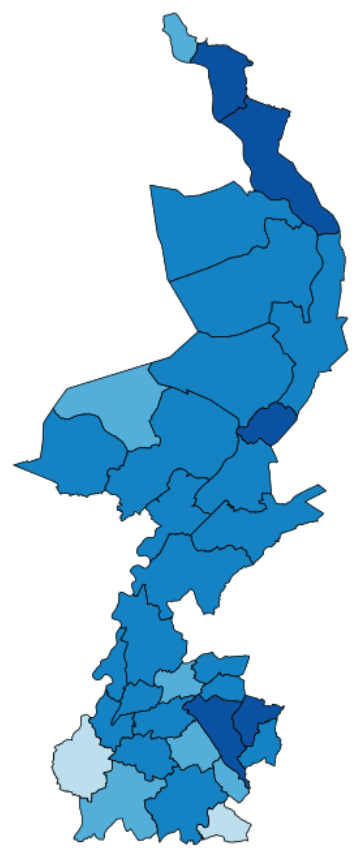

2018

$=40-50$

$\square 30-40$

$\square 20-30$

$\square 10-20$

$\square 0-10$

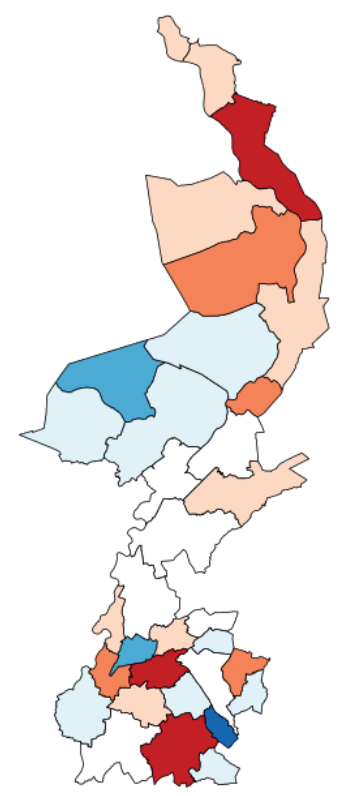

Groei 2015 - 2018

$=25-100$

$\square 15-25$

$\square 5-15$

$\square-5-5$

ㅁ-15 - -5

$\square-25--15$

$\square-100--25$

\section{Tabel 2}

Herkomst van Limburgse NEETs

\begin{tabular}{|c|c|c|c|c|c|}
\hline Herkomstgroepering & Langduring & Nieuwkomers & Onderwijs Verlaters & Werkverlaters & Totaal \\
\hline \multirow[t]{2}{*}{ Antilliaans/Arubaans } & 51 & - & 48 & - & 99 \\
\hline & $1 \%$ & - & $1 \%$ & - & $1 \%$ \\
\hline \multirow[t]{2}{*}{ Marokkaans } & 210 & 39 & 218 & 27 & 494 \\
\hline & $4 \%$ & $0,5 \%$ & $4 \%$ & $4 \%$ & $2,5 \%$ \\
\hline \multirow[t]{2}{*}{ Surinaams } & 25 & - & 27 & - & 52 \\
\hline & $0,5 \%$ & - & $0,5 \%$ & - & $0,5 \%$ \\
\hline \multirow[t]{2}{*}{ Turks } & 123 & 140 & 159 & 26 & 448 \\
\hline & $2 \%$ & $2 \%$ & $3 \%$ & $4 \%$ & $2 \%$ \\
\hline \multirow[t]{2}{*}{ Westerse migranten } & 1.136 & 5.528 & 968 & 114 & 7.746 \\
\hline & $20 \%$ & $69 \%$ & $16 \%$ & $16 \%$ & $38 \%$ \\
\hline \multirow[t]{2}{*}{ Autochtoon } & 3.360 & 67 & 4.099 & 506 & 8.032 \\
\hline & $60 \%$ & $1 \%$ & $70 \%$ & $72 \%$ & $40 \%$ \\
\hline \multirow[t]{2}{*}{ Overig niet-Westers } & 674 & 2.231 & 391 & 31 & 3.327 \\
\hline & $12 \%$ & $28 \%$ & $7 \%$ & $4 \%$ & $16 \%$ \\
\hline \multirow[t]{2}{*}{ Total } & 5.579 & 8.023 & 5.910 & 707 & 20.219 \\
\hline & $100 \%$ & $100 \%$ & $100 \%$ & $100 \%$ & $100 \%$ \\
\hline
\end{tabular}




\section{Factsheet}

ROA-F-2020/4

Tabel $3 a$

Vijf belangrijkste herkomstlanden van langdurige NEETs in

Limburg

\begin{tabular}{|l|c|c|}
\hline Herkomstland & N & $\%$ \\
\hline Nederland & 3.360 & 60,23 \\
\hline Bondsrepubliek Duitsland & 341 & 6,11 \\
\hline Marokko & 210 & 3,76 \\
\hline België & 125 & 2,24 \\
\hline Turkije & 123 & 2,2 \\
\hline
\end{tabular}

Nadere studie van geboortelanden laat zien dat zo'n $\mathbf{7 0} \%$ van alle nieuwkomers van Westerse herkomst is. Zo'n $25 \%$ van de nieuwkomers in Limburg is Duits, $8 \%$ komt uit de VS, en 5,75\% uit Syrie. Inzoomend op gemeenten Vaals en Maastricht laat zien dat in Vaals zo'n $80 \%$ van de nieuwkomers Duits is. In Tabel 3b zien we dat in Maastricht 25,8\% van de nieuwkomers Duits is; $11 \%$ komt uit de VS, 5,53\% uit Italië, en 5\% uit België. Dit zijn waarschijnlijk studenten.

Tabel 3b

Vijf belangrijkste herkomstlanden van NEET-nieuwkomers in Maastricht

\begin{tabular}{|l|c|c|}
\hline Herkomstland & N & $\%$ \\
\hline Bondsrepubliek Duitsland & 1.484 & 25,79 \\
\hline Verenigde Staten van Amerika & 630 & 10,95 \\
\hline Italië & 318 & 5,53 \\
\hline België & 289 & 5,02 \\
\hline China & 221 & 3,84 \\
\hline
\end{tabular}

Wanneer we de genderverdeling van de verschillende NEET-clusters bekijken (Tabel 4), valt op dat er geen erg grote verschillen bestaan. Mannen hebben een iets grotere kans om langdurig NEET te worden en een iets grotere kans om via het onderwijs NEET te worden. Vrouwen zijn iets vaker nieuwkomers.

Tabel 4

Genderverdeling van NEET-nieuwkomers in Limburg (percentage)

\begin{tabular}{|l|c|c|}
\hline & \multicolumn{2}{|c|}{ Geslacht } \\
\hline NEET Type 2018 & Mannen & Vrouwen \\
\hline Langdurig & 29,03 & 26,18 \\
\hline Nieuwkomers & 35,21 & 44,05 \\
\hline Onderwijsverlaters & 32,29 & 26,23 \\
\hline Werkverlaters & 3,46 & 3,53 \\
\hline
\end{tabular}

Laten we ten slotte nagaan welke rol onderwijs speelt. We doen dat op drie manieren. In Tabel 5 zien we welke opleidingen de verschillende NEETs volgden in $2014 .^{3}$ Relatief veel langdurige NEETs komen uit het speciaal of praktijkonderwijs. Dit zijn opleidingen die vrijstellen van de kwalificatieplicht en toch voorbereiden op de arbeidsmarkt. Onze analyse maakt aannemelijk dat dit risico-opleidingen zijn. Ook MBO-ers op niveau-2 hebben een relatief hoge kans om langdurig NEET te worden. In algemene zin geldt, dat MBO-ers die NEET worden, voornamelijk in die positie komen nadat ze eerst werk hebben gehad.

Tabel 5

Verdeling over opleidingsniveaus van NEET-groepen in Limburg (percentage)

\begin{tabular}{|l|c|c|c|}
\hline & \multicolumn{3}{|c|}{ NEET in 0ctober 2018 } \\
\hline Onderwijs 2014 & Langdurig & $\begin{array}{c}\text { Onderwijs } \\
\text { verlaters }\end{array}$ & Werkverlaters \\
\hline Speciaal of Praktijkonderwijs* & 7,85 & 23,02 & 4,05 \\
\hline VMB0 & 0,96 & 21,02 & 3,56 \\
\hline HAV0/VW0 & 1,07 & 10,63 & 2,19 \\
\hline MB0 (niveau onbekend) & 0,25 & 0,33 & 1,13 \\
\hline MB01 & 1,56 & 1,17 & 1,3 \\
\hline MB02 & 3,97 & 5,12 & 10,69 \\
\hline MB03 & 1,97 & 4,65 & 9,55 \\
\hline MB04 & 1,76 & 6,64 & 8,02 \\
\hline HB0/W0 & 1,93 & 13,88 & 6,96 \\
\hline Niet in onderwijs in 2014 & 78,69 & 13,54 & 52,55 \\
\hline Totaal & 100 & 100 & 100 \\
\hline Bronn
\end{tabular}

Bron: CBS, eigen berekeningen.

Het gaat hier om mensen die NEET waren in 2018 en in 2014 in het onderwijs waren ingeschreven. ${ }^{*}$ Er zaten geen mensen op de basisschool in 2014.

De tabel is minder informatief omdat een groot deel van de NEETs in 2018 ook in 2014 al niet meer in het onderwijs zat. Tabel 6 vergelijkt daarom het hoogst behaalde opleidingsniveau van de NEETs uit 2018 in verschillende groepen. In alle drie de NEET-categorieën is het aantal jongeren zonder startkwalificatie veruit het hoogst. Het gaat dan in meerderheid om mensen die als hoogste niveau het basisonderwijs, een VMBO-opleiding, of een mbo-opleiding op niveau 1 hebben. Ook uit deze figuur blijkt dat van de MBO afgestudeerden de schoolverlaters op niveau 2 de slechtste kansen hebben. Met name onder de groep jongeren die via een baan NEET worden, zijn zij erg hoog vertegenwoordigd.

3 Dit kunnen we niet doen voor de nieuwkomers, want die stonden toen niet in het Nederlandse onderwijs ingeschreven. Een groot deel van de NEET in 2018 stond in 2014 al niet meer ingeschreven in het onderwijs. 


\section{Neet aan 't werk, neet op sjoël, neet op training}

Tabel 6

Hoogst bereikte opleidingsniveaus van NEET-groepen in Limburg (percentages en absolute aantallen)

\begin{tabular}{|c|c|c|c|c|c|c|}
\hline \multirow[t]{3}{*}{ Hoogste opleiding 2014} & \multicolumn{6}{|c|}{ NEET in October 2018} \\
\hline & \multicolumn{2}{|c|}{ Langdurig } & \multicolumn{2}{|c|}{ Onderwijsverlaters } & \multicolumn{2}{|c|}{ Werkverlaters } \\
\hline & $\%$ & N & $\%$ & N & $\%$ & $\mathrm{~N}$ \\
\hline Niet in onderwijs & 22,04 & 1.076 & 5,57 & 353 & 11,34 & 140 \\
\hline Basisonderwijs & 31,31 & 1.528 & 45,36 & 2.877 & 9,72 & 120 \\
\hline VMBO-G/T HAVO VWO & 9,47 & 462 & 12,95 & 821 & 12,31 & 152 \\
\hline VMBO-B/K MB01 & 21 & 1.025 & 12,8 & 812 & 24,29 & 300 \\
\hline HAVO/VWO & 4,43 & 216 & 16,64 & 1.055 & 8,26 & 102 \\
\hline MBO2 & 5,9 & 288 & 2,66 & 169 & 16,28 & 201 \\
\hline MBO3 & 2,83 & 138 & 1,21 & 77 & 7,53 & 93 \\
\hline MBO4 & 2,25 & 110 & 2 & 127 & 7,53 & 93 \\
\hline HBO/WO & 0,68 & 33 & 0,77 & 49 & 2,27 & 28 \\
\hline Totaal & 100 & 4.881 & 100 & 6.342 & 100 & 1.235 \\
\hline
\end{tabular}

In Tabel 7 bezien we ten slotte in welke mate de NEETs uit 2018 een startkwalificatie hadden behaald in 2014. Ook hieruit blijkt duidelijk dat met name onder de langdurige NEETs het aantal schoolverlaters dat geen startkwalificatie heeft behaald, erg hoog is.

Tabel 7

Verdeling over het hebben van een startkwalificatie in 2014 (percentage)

\begin{tabular}{|l|c|c|c|c|}
\hline \multirow{2}{*}{ Startkwalificatie 2014 } & \multicolumn{4}{|c|}{ NEET in October 2018 } \\
& Langdurig & Nieuw & Onderwijs & Werk \\
& & komers & verlaters & verlaters \\
\hline Niet behaald & 62 & - & 71 & 46,5 \\
\hline Behaald & 16 & - & 23 & 42,5 \\
\hline Niet in register & 22 & - & 6 & 11 \\
\hline Totaal & 100 & - & 100 & 100 \\
\hline
\end{tabular}

Bron: CBS, eigen berekeningen.

Het gaat hier om mensen die NEET waren in 2018 en in 2014 in het onderwijs waren ingeschreven

\section{Aanbevelingen}

Wat hebben we aan deze gegevens? Wat betekenen ze voor beleid van scholen, gemeenten, en de provincie? We doen op verzoek van de Provincie Limburg een viertal concrete aanbevelingen, op basis van deze analyses en bevindingen uit de literatuur:

1. Overdrijf niet. Limburg lijkt het flink slechter te doen dan andere Nederlandse gemeenten. De toename van het aantal NEETs lijkt echter vooral toe te schrijven aan een toename in twee gemeenten: Vaals en Maastricht. Deze toename wordt bijna helemaal gedreven door een toename van nieuwkomers. Dat zijn voor het overgrote deel jongeren van Westerse afkomst. We denken daarom dat het hier voornamelijk gaat om studenten of mensen die werkzaam zijn in Duitsland of België.

2. Pas beleid aan op de groep. Dat wil niet zeggen dat er geen probleem is. Met name de toename van het aantal langdurige NEETs in verschillende regio's is zorgwekkend. Uit een enquete van het CBS in 2017 blijkt, dat zo'n 40\% van de NEETs in Nederland "niet kan of wil werken". ${ }^{4}$ Het ligt in de rede dat een groot deel van de langdurige NEETs in deze categorie valt. Als het landelijke beeld overeenkomt met het beeld in Limburg, mogen we verwachten dat ongeveer de helft (landelijk: $53 \%$ ) van deze mensen langdurig ziek is of arbeidsgehandicapt. Ongeveer 20\% van de mensen kiest ervoor niet te werken, vanwege studieplannen (12\% van de Nederlandse NEETs zit tussen twee opleidingen in) of zorgtaken (6\%). Reïntegratiebeleid zou voor deze groep voornamelijk gericht kunnen zijn op de ongeveer $30 \%$ van de mensen die om verschillende andere redenen langdurig thuiszitten. Voor deze groep is gericht reïntegratiebeleid noodzakelijk. Daarbij geldt dat een actieve, persoonlijke benadering waarschijnlijk het meest effectief is. ${ }^{5}$

3. Bestrijd voortijdig schoolverlaten (VSV). Een groot deel van de Limburgse NEETs komt rechtstreeks uit het onderwijs. Deze onderwijsverlatende NEETs komen

4 Perez, Sebastian Alejandro \& Hendrika Lautenbach (2018) NEETs: jongeren die geen opleiding volgen en niet werken. Den Haag/ Heerlen: Centraal Bureau voor de Statistiek

5 Oostveen Adriaan en collega's. (2017). Matchen op Werk tweede monitor: eindrapportage. Regioplan Publicatienr. 15113. In opdracht van MinSZW 


\section{Factsheet}

voor een groot deel uit het MBO; een deel van deze onderwijsverlaters is voortijdig schoolverlater. RMCs, gemeenten en scholen moeten de handen ineen slaan en actief beleid voeren om VSV tegen te gaan. Het bestrijden van VSV is waarschijnlijk de meest effectieve strategie om het aantal NEETs in Limburg terug te brengen.

\section{Geef scholieren een diploma waar ze iets aan} hebben. Maar ook schoolverlaters mét diploma kunnen langdurig buiten de arbeidsmarkt terechtkomen. Met name scholieren die een diploma op MBO niveau 2 behalen worden voorgesorteerd voor een langdurig bestaan buiten de arbeidsmarkt. Succesvol beleid zou gericht kunnen zijn op verbeterde doorstroom in plaats van succesvolle uitstroom. Scholieren met een $\mathrm{MBO}_{2}$ diploma zouden zoveel mogelijk gestimuleerd moeten worden om door te stromen naar MBO opleidingen op niveau 3. Ook verdient het aanbeveling goed naar de arbeidsmarktkansen van de verschillende opleidingen te kijken. Veel NEETs die uit het MBO komen vallen buiten de arbeidsmarkt nadat ze eerst werk hebben gehad. Dat doet vermoeden dat deze NEETs te weinig vaardigheden hebben om zich op de arbeidsmarkt te kunnen handhaven. Door sterkere institutionele bindingen tussen werkgevers en het Limburgse beroepsonderwijs kunnen vraag en aanbod van beroepsspecifieke vaardigheden beter op elkaar worden afgestemd en de macrodoelmatigheid van het Limburgse beroepsonderwijs worden verhoogd. 


\section{Neet aan 't werk, neet op sjoël, neet op training}

\section{Appendix}

\begin{tabular}{|c|c|c|c|c|c|c|c|c|c|}
\hline \multirow[b]{3}{*}{ Jaar } & \multicolumn{9}{|c|}{ RMC Zuid } \\
\hline & \multicolumn{5}{|c|}{ Absolute aantallen } & \multicolumn{4}{|c|}{ Percentages } \\
\hline & Gemeente & L & N & 0 & W & L & $\mathrm{N}$ & 0 & W \\
\hline 2015 & Beek & 68 & & 82 & & 40,5 & & 48,8 & \\
\hline 2018 & Beek & 44 & 14 & 61 & 10 & 34,1 & 10,9 & 47,3 & 7,8 \\
\hline 2015 & Brunssum & 186 & 13 & 190 & 37 & 43,7 & 3,1 & 44,6 & 8,7 \\
\hline 2018 & Brunssum & 140 & 37 & 152 & 21 & 40,0 & 10,6 & 43,4 & 6,0 \\
\hline 2015 & Echt-Susteren & 174 & 85 & 204 & 31 & 35,2 & 17,2 & 41,3 & 6,3 \\
\hline 2018 & Echt-Susteren & 109 & & 143 & & 34,5 & & 45,3 & \\
\hline 2015 & Eijsden-Margraten & 87 & 25 & 169 & 24 & 28,5 & 8,2 & 55,4 & 7,9 \\
\hline 2018 & Eijsden-Margraten & 73 & 37 & 129 & 13 & 29,0 & 14,7 & 51,2 & 5,2 \\
\hline 2015 & Gulpen-Wittem & 59 & 57 & 83 & 10 & 28,2 & 27,3 & 39,7 & 4,8 \\
\hline 2018 & Gulpen-Wittem & 46 & & 61 & & 36,8 & & 48,8 & \\
\hline 2015 & Heerlen & 808 & 160 & 762 & 121 & 43,7 & 8,6 & 41,2 & 6,5 \\
\hline 2018 & Heerlen & 605 & 219 & 561 & 67 & 41,7 & 15,1 & 38,6 & 4,6 \\
\hline 2015 & Kerkrade & 400 & 101 & 337 & 51 & 45,0 & 11,4 & 37,9 & 5,7 \\
\hline 2018 & Kerkrade & 274 & 108 & 277 & 35 & 39,5 & 15,6 & 39,9 & 5,0 \\
\hline 2015 & Landgraaf & 174 & 38 & 265 & 29 & 34,4 & 7,5 & 52,4 & 5,7 \\
\hline 2018 & Landgraaf & 185 & 39 & 196 & 25 & 41,6 & 8,8 & 44,0 & 5,6 \\
\hline 2015 & Maastricht & 1279 & 4475 & 1358 & 148 & 17,6 & 61,6 & 18,7 & 2,0 \\
\hline 2018 & Maastricht & 1279 & 5754 & 971 & 79 & 15,8 & 71,2 & 12,0 & 1,0 \\
\hline 2015 & Meerssen & 73 & 20 & 118 & 22 & 31,3 & 8,6 & 50,6 & 9,4 \\
\hline 2018 & Meerssen & 74 & & 94 & & 37,2 & & 47,2 & \\
\hline 2015 & Nuth & 39 & 13 & 74 & 11 & 28,5 & 9,5 & 54,0 & 8,0 \\
\hline 2018 & Nuth & 46 & & 61 & & 37,7 & & 50,0 & \\
\hline 2015 & Onderbanken & 31 & & 49 & & 35,2 & & 55,7 & \\
\hline 2018 & Onderbanken & 25 & & 35 & & 34,7 & & 48,6 & \\
\hline 2015 & Schinnen & 49 & 52 & 85 & 12 & 24,7 & 26,3 & 42,9 & 6,1 \\
\hline 2018 & Schinnen & 30 & & 55 & & 28,3 & & 51,9 & \\
\hline 2015 & Simpelveld & 37 & & 57 & & 33,6 & & 51,8 & \\
\hline 2018 & Simpelveld & 24 & & 54 & & 24,5 & & 55,1 & \\
\hline 2015 & Sittard-Geleen & 635 & 117 & 748 & 148 & 38,5 & 7,1 & 45,4 & 9,0 \\
\hline 2018 & Sittard-Geleen & 532 & 152 & 592 & 81 & 39,2 & 11,2 & 43,6 & 6,0 \\
\hline 2015 & Stein & 91 & 22 & 163 & 27 & 30,0 & 7,3 & 53,8 & 8,9 \\
\hline 2018 & Stein & 76 & 20 & 115 & 16 & 33,5 & 8,8 & 50,7 & 7,0 \\
\hline 2015 & Vaals & 44 & 125 & & & 17,1 & 48,6 & & \\
\hline 2018 & Vaals & 100 & 521 & & & 14,8 & 77,1 & & \\
\hline 2015 & Valkenburg ad Geul & 58 & 16 & 101 & 15 & 30,5 & 8,4 & 53,2 & 7,9 \\
\hline 2018 & Valkenburg ad Geul & 55 & 28 & 70 & 10 & 33,7 & 17,2 & 42,9 & 6,1 \\
\hline 2015 & Voerendaal & 34 & & 65 & & 30,1 & & 57,5 & \\
\hline 2018 & Voerendaal & 22 & & 50 & & 25,9 & & 58,8 & \\
\hline
\end{tabular}




\section{Factsheet}

ROA-F-2020/4

\begin{tabular}{|c|c|c|c|c|c|c|c|c|c|}
\hline \multirow[b]{3}{*}{ Jaar } & \multicolumn{9}{|c|}{ RMC Noord- en Midden-Limburg } \\
\hline & & \multicolumn{4}{|c|}{ Absolute aantallen } & \multicolumn{4}{|c|}{ Percentages } \\
\hline & Gemeente & L & $\mathrm{N}$ & 0 & W & $\mathrm{L}$ & $\mathrm{N}$ & 0 & W \\
\hline 2015 & Beesel & 47 & & 77 & & 33,3 & & 54,6 & \\
\hline 2018 & Beesel & 51 & & 56 & & 41,1 & & 45,2 & \\
\hline 2015 & Bergen (L.) & 49 & 13 & 66 & 21 & 32,9 & 8,7 & 44,3 & 14,1 \\
\hline 2018 & Bergen (L.) & 47 & & 38 & & 46,1 & & 37,3 & \\
\hline 2015 & Gennep & 87 & 11 & 109 & 16 & 39,0 & 4,9 & 48,9 & 7,2 \\
\hline 2018 & Gennep & 63 & 12 & 62 & 11 & 42,6 & 8,1 & 41,9 & 7,4 \\
\hline 2015 & Horst aan de Maas & 102 & 35 & 200 & 43 & 26,8 & 9,2 & 52,6 & 11,3 \\
\hline 2018 & Horst aan de Maas & 100 & 55 & 127 & 22 & 32,9 & 18,1 & 41,8 & 7,2 \\
\hline 2015 & Leudal & 160 & 84 & 187 & 35 & 34,3 & 18,0 & 40,1 & 7,5 \\
\hline 2018 & Leudal & 110 & 63 & 161 & 14 & 31,6 & 18,1 & 46,3 & 4,0 \\
\hline 2015 & Maasgouw & 98 & 30 & 127 & 18 & 35,9 & 11,0 & 46,5 & 6,6 \\
\hline 2018 & Maasgouw & 79 & & 108 & & 36,1 & & 49,3 & \\
\hline 2015 & Mook en Middelaar & 17 & & 39 & & 25,0 & & 57,4 & \\
\hline 2018 & Mook en Middelaar & 18 & & 35 & & 28,6 & & 55,6 & \\
\hline 2015 & Nederweert & 53 & 12 & 66 & 21 & 34,9 & 7,9 & 43,4 & 13,8 \\
\hline 2018 & Nederweert & 35 & & 64 & & 27,3 & & 50,0 & \\
\hline 2015 & Peel en Maas & 137 & 54 & 174 & 37 & 34,1 & 13,4 & 43,3 & 9,2 \\
\hline 2018 & Peel en Maas & 107 & 44 & 178 & 16 & 31,0 & 12,8 & 51,6 & 4,6 \\
\hline 2015 & Roerdalen & 70 & 24 & 115 & 20 & 30,6 & 10,5 & 50,2 & 8,7 \\
\hline 2018 & Roerdalen & 57 & & 75 & & 34,5 & & 45,5 & \\
\hline 2015 & Roermond & 379 & 97 & 428 & 88 & 38,2 & 9,8 & 43,1 & 8,9 \\
\hline 2018 & Roermond & 295 & 86 & 300 & 58 & 39,9 & 11,6 & 40,6 & 7,8 \\
\hline 2015 & Venlo & 463 & 270 & 646 & 162 & 30,0 & 17,5 & 41,9 & 10,5 \\
\hline 2018 & Venlo & 499 & 408 & 532 & 78 & 32,9 & 26,9 & 35,1 & 5,1 \\
\hline 2015 & Venray & 150 & 45 & 219 & 51 & 32,3 & 9,7 & 47,1 & 11,0 \\
\hline 2018 & Venray & 149 & 56 & 186 & 28 & 35,6 & 13,4 & 44,4 & 6,7 \\
\hline 2015 & Weert & 273 & 69 & 304 & 68 & 38,2 & 9,7 & 42,6 & 9,5 \\
\hline 2018 & Weert & 230 & 127 & 261 & 29 & 35,5 & 19,6 & 40,3 & 4,5 \\
\hline
\end{tabular}




\section{LIMBURG}

Deze factsheet is een onderdeel van het meerjarenprogramma 4 Limburg dat een bijdrage wil leveren om de Limburgse samenleving meer duurzaam, vitaal en inclusief te maken. Het doel van dit programma is om, in nauwe samenwerking met de Universiteit Maastricht, Provincie Limburg en ketenpartners zoals gemeenten, UWV en bedrijfsleven, via een trendbreuk de arbeidsparticipatie én de vitaliteit in Limburg naar een hoger niveau te tillen. Voor de Limburgse welvaartsontwikkeling is het van groot belang dat jongeren met de juiste bagage aan de start verschijnen en niet al te vroeg afhankelijk worden van een uitkering. Als opstap voor het te voeren beleid geeft deze factsheet inzicht in de ontwikkeling van de groep jongeren die geen onderwijs volgen of werk hebben look wel aangeduid als de NEETs: "Not in Employment, Education or Training") en inzicht in de omvang van de problematiek in de verschillende gemeentes in Limburg.

\section{Colofon}

( ) Researchcentrum voor Onderwijs en Arbeidsmarkt Niets uit deze uitgave mag op enige manier worden verveelvoudigd zonder voorafgaande schriftelijke toestemming van de directeur van het ROA.

Researchcentrum voor Onderwijs en Arbeidsmarkt

Maastricht University

School of Business and Economics

secretary-roa-sbe@maastrichtuniversity.nl www.roa.nl

\section{Vormgeving}

ROA secretariaat, Maastricht 